Polymer Journal, Vol. 39, No. 7, pp. 690-695 (2007)

(C) 2007 The Society of Polymer Science, Japan

\title{
Synthesis and Properties of Helical Poly(macromonomer) Consisting of Polyacetylene Main Chain and Poly(methyl methacrylate) Side Chains
}

\author{
Masashi SHIOTSUKI, Wei Zhang, and Toshio MASUdA ${ }^{\dagger}$ \\ Department of Polymer Chemistry, Graduate School of Engineering, Kyoto University, \\ Katsura Campus, Kyoto 615-8510, Japan
}

(Received March 9, 2007; Accepted April 4, 2007; Published May 16, 2007)

\begin{abstract}
The Rh-catalyzed polymerization of an acetylene-terminated poly(methyl methacrylate) (PMMA) macromonomer (M-PMMA) provided a helical poly(macromonomer), poly(M-PMMA) $\left[M_{\mathrm{w}}\right.$ up to 136,000 , weightaverage degree of polymerization $\left(\mathrm{DP}_{\mathrm{w}}\right)=80$ ], consisting of a polyacetylene main chain and PMMA side chains. The macromonomer M-PMMA was synthesized by ATRP of MMA initiated by a functionalized initiator, 2-bromo2-methylpropionic acid (S)-1-methylpropargyl ester (I), in the presence of $\mathrm{CuBr} / N, N, N^{\prime}, N^{\prime \prime}, N^{\prime \prime}$-pentamethyldiethylenetriamine (PMDETA) catalyst/ligand system in toluene at $70^{\circ} \mathrm{C}$. Poly(M-PMMA) was a light yellow solid soluble in common organic solvents such as THF, $\mathrm{CHCl}_{3}$, and toluene. Poly(M-PMMA) exhibited a strong $\mathrm{CD}$ signal at around $350-357 \mathrm{~nm}$ with molar ellipticities $([\theta])$ of $+26300-+27500 \mathrm{deg} \mathrm{cm}^{2} \mathrm{dmol}^{-1}$ in THF, $\mathrm{CHCl}_{3}$, toluene and DMF. This indicates that it possessed a predominantly one-handed helical conformation. Poly(M-PMMA) had stable helical conformation irrespective of solvents and temperature. [doi:10.1295/polymj.PJ2006260]
\end{abstract}

KEY WORDS Helical Polymer / Poly(macromonomer) / Polyacetylenes /

The synthesis of helical polymers is an important field in macromolecular science as they are used in a wide variety of potential applications based on the chiral structure. ${ }^{1-5}$ There are several classes of wellordered synthetic helical polymers including poly(alkyl methacrylates) ${ }^{6-9}$ polychloral, ${ }^{10,11}$ polyisocyanides, ${ }^{12-15}$ polyisocyanates, ${ }^{16-19}$ and polysilanes. ${ }^{20-23}$ Besides, some helical polyacetylenes have been synthesized by Rh-catalyzed polymerization of acetylenic monomers having chiral side groups such as chiral carboxylic acids, ${ }^{24-29}$ alcohols, ${ }^{30-33}$ amino acids, ${ }^{34-40}$ sugars $^{41-43}$ and terpenes ${ }^{44}$ as the helical sources. Recently, our laboratory reported that (S)-1-methylpropargyl alcohol served as a powerful helical source for substituted polyacetylenes. ${ }^{45}$ The polymers derived from the alcohol and its esters form helical structures with predominantly one-handed screw sense. The remarkable ability of such a small chiral moiety to induce helicity is probably due to location of the chiral group adjacent to the main chain. Thus, a wide variety of helical polymers are attainable by transformation of the hydroxyl group of chiral 1-methylpropargyl alcohol into other functional groups.

Poly(macromonomers) exhibit interesting properties different from those of their linear counterparts in solid state and solution. ${ }^{46-48}$ Different from polyacetylenes derived from small acetylenic monomers, the polymerization of macromonomers bearing a polymerizable acetylene unit can lead to poly- (macromonomers) consisting of a polyacetylene main chain and polymer side chains such as polystyrene (PS) ${ }^{49,50}$ poly(methyl methacrylate) (PMMA), ${ }^{50}$ poly(ethylene oxide) (PEO), ${ }^{51}$ and poly(dimethylsiloxane). ${ }^{52}$ For example, novel cylindrical polymer brushes composed of a poly(phenylacetylene) main chain and either PS or PMMA side chains featuring high molecular weight above one million or narrow molecular weight distribution have been synthesized by the polymerization of phenylacetylene-terminated PS or PMMA macromonomers. ${ }^{50}$

To the best of our knowledge, there have been few examples of helical poly(macromonomers) in the literature. One example reported by Yashima and coworkers is a series of optically active, stereoregular poly(phenylacetylene)s by the polymerization of polypeptide macromonomers having a phenylacetylene chain end. ${ }^{53}$ Helical poly(macromonomers) are fascinating because they may show unique properties not observed in linear helical polymers. We have previously reported the synthesis of a helical poly(macromonomer) derived from a chiral acetylene-terminated PS macromonomer. ${ }^{54}$ The PS macromonomer was prepared via the atom transfer radical polymerization $(\text { ATRP })^{55-58}$ of styrene employing an initiator 2-bromo-2-methylpropionic acid (S)-1-methylpropargyl ester (l) derived from (S)-1-methylpropargyl alcohol. To expand the scope of helical poly(macromonomers), here we report the synthesis of poly(macromonomer) composed of a polyacetylene main chain

${ }^{\dagger}$ To whom correspondence should be addressed (Tel: +81-75-383-2589, Fax: +81-75-383-2590, E-mail: masuda@adv.polym.kyoto-u.ac.jp). 
and PMMA side chains, which was prepared the polymerization of a PMMA macromonomer obtained by ATRP of MMA using initiator $\mathbf{1}$.

\section{EXPERIMENTAL}

\section{Measurements}

${ }^{1} \mathrm{H}$ NMR spectra were recorded on a JEOL EX-400 spectrometer using chloroform- $d\left(\mathrm{CDCl}_{3}\right)$ as a solvent with tetramethylsilane as internal reference $(\delta=0)$. The weight-average molecular weight $\left(M_{\mathrm{w}}\right)$, number-average molecular weights $\left(M_{\mathrm{n}}\right)$ and polydispersity ratios $\left(M_{\mathrm{w}} / M_{\mathrm{n}}\right)$ of the obtained polymers were determined by gel permeation chromatography (GPC) on a Jasco Gulliver System (PU-980, CO-965, RI930, and UV-1570) equipped with a series of PS gel columns (Shodex KF805L $\times$ 3, bead size: $10 \mu \mathrm{m}$, molecular weight range up to $4 \times 10^{6}$, flow rate $1 \mathrm{~mL} /$ min), using THF as an eluent at $40^{\circ} \mathrm{C}$ with a PS calibration. Specific rotations $\left([\alpha]_{\mathrm{D}}\right)$ were measured on a JASCO DIP-1000 digital polarimeter with a sodium lamp as a light source. Circular dichroism (CD) and UV-vis spectra were recorded on a JASCO J-820 spectropolarimeter using a quartz cell (thickness: $1 \mathrm{~cm})$.

\section{Materials}

Copper(I) bromide (CuBr) (Aldrich, 98\%), N,N,$N^{\prime}, N^{\prime \prime}, N^{\prime \prime}$-pentamethyldiethylenetriamine (PMDETA) (Wako, Japan 98\%) were used as received. Methyl methacrylate (MMA) (Wako, Japan 98\%) was distilled from $\mathrm{CaH}_{2}$ under reduced pressure and stored at $-30{ }^{\circ} \mathrm{C}$ under argon. Toluene and $\mathrm{CHCl}_{3}$ were distilled from $\mathrm{CaH}_{2}$ under argon. $o$-Dichlorobenzene was purified by distillation from $\mathrm{CaH}_{2}$ under reduced pressure. Tetrahydrofuran (THF) was distilled from sodium benzophenone ketyl under argon. The ATRP initiator, 2-bromo-2-methylpropionic acid $(S)$-1-methylpropargyl ester (1) ${ }^{45}$ and (nbd) $\mathrm{Rh}^{+}\left[\eta^{6}-\left(\mathrm{C}_{6} \mathrm{H}_{5}\right) \mathrm{B}^{-}\right.$$\left.\left(\mathrm{C}_{6} \mathrm{H}_{5}\right)_{3}\right]$ (nbd $=2,5$-norbornadiene $)^{59}$ were synthesized according to the literature.

\section{Synthesis of M-PMMA}

Methyl methacrylate $(3.28 \mathrm{~g}, 32.8 \mathrm{mmol})$, initiator 1 (0.718 g, $3.28 \mathrm{mmol}), \mathrm{CuBr}(0.235 \mathrm{~g}, 1.64 \mathrm{mmol})$, and toluene $(1.5 \mathrm{~mL})$ were placed in a $40-\mathrm{mL}$ flask equipped with a three-way stopcock, and the mixture was subjected to three freeze-pump-thaw cycles. The flask was placed in an oil bath preheated to $70^{\circ} \mathrm{C}$, and PMDETA $(0.284 \mathrm{~g}, 1.64 \mathrm{mmol})$ was added with an argon-purged syringe. After 10 minutes, the mixture was cooled, diluted with THF, and passed through a neutral alumina column to remove the catalyst. The solution was concentrated to $c a .8 \mathrm{~mL}$ by rotary evaporation. The product was precipitated in a large
Table I. Polymerization of M-PMMA $\left(M_{\mathrm{w}}=1690\right.$, $\left.M_{\mathrm{w}} / M_{\mathrm{n}}=1.3\right)$ with $(\mathrm{nbd}) \mathrm{Rh}^{+}\left[\eta^{6}-\left(\mathrm{C}_{6} \mathrm{H}_{5}\right) \mathrm{B}^{-}\left(\mathrm{C}_{6} \mathrm{H}_{5}\right)_{3}\right]^{\mathrm{a}}$

\begin{tabular}{ccccccc}
\hline Run & $\begin{array}{c}\text { [M-PMMA }] \\
(\mathrm{M})\end{array}$ & $\begin{array}{c}{[\mathrm{Rh}]} \\
(\mathrm{mM})\end{array}$ & $\begin{array}{c}\text { Yield } \\
(\%)\end{array}$ & $M_{\mathrm{w}}{ }^{\mathrm{c}}$ & $M_{\mathrm{w}} / M_{\mathrm{n}}{ }^{\mathrm{c}}$ & $\mathrm{DP}_{\mathrm{w}}{ }^{\mathrm{d}}$ \\
\hline 1 & 0.10 & 5.0 & 73 & 48,200 & 4.0 & 29 \\
2 & 0.10 & 10 & 81 & 32,500 & 3.6 & 19 \\
3 & 0.20 & 5.0 & 64 & 105,000 & 8.4 & 62 \\
4 & 0.20 & 10 & 85 & 136,000 & 5.6 & 80 \\
\hline
\end{tabular}

${ }^{\mathrm{a} C}$ Conditions: in THF, $30^{\circ} \mathrm{C}, 24 \mathrm{~h}$. ${ }^{\mathrm{b}}$ Diethyl ether-insoluble product. ${ }^{\mathrm{c}}$ Estimated by GPC in THF on the basis of a PS calibration. ${ }^{\mathrm{d}}$ Weight-average degree of polymerization (calculated by $\left.M_{\mathrm{w}, \text { poly }(\mathrm{M}-\mathrm{PMMA})} / M_{\mathrm{w}, \mathrm{M} \text {-PMMA }}, M_{\mathrm{w}, \mathrm{M}-\mathrm{PMMA}}=1690\right)$.

amount of hexane and dried under reduced pressure to give $1.70 \mathrm{~g}(52 \%)$ of M-PMMA as a white powder. GPC $($ THF $): M_{\mathrm{w}}=1690, M_{\mathrm{w}} / M_{\mathrm{n}}=1.3$. Weightaverage degree of polymerization $\left(\mathrm{DP}_{\mathrm{n}}\right)=16 .[\alpha]_{\mathrm{D}}=$ $-10^{\circ}\left(c=0.10 \mathrm{~g} / \mathrm{dL}\right.$, in THF, r.t.). ${ }^{1} \mathrm{H}$ NMR (400 $\mathrm{MHz}, \mathrm{CDCl}_{3}$ ): $\delta=5.35$ (t, $\mathrm{CHCH}_{3}$ ), 3.73 (s, terminal $\mathrm{CO}_{2} \mathrm{CH}_{3}$ ), 3.70-3.30 (broad s, $\mathrm{CO}_{2} \mathrm{CH}_{3}$ on backbone), 2.80-2.60 (broad $\mathrm{m}, \mathrm{CH}_{2}$ of terminal MMA moiety), 2.39 (s, $\equiv \mathrm{C}-H$ ), 2.20-0.60 (broad $\mathrm{m}, \mathrm{CH}_{2}$ and $\mathrm{CH}_{3}$ of backbone), 1.45 (d, $\mathrm{CHCH}_{3}$ ).

\section{Polymerization of M-PMMA}

A typical procedure is as follows (Run 4, Table I): A solution of $(\mathrm{nbd}) \mathrm{Rh}^{+}\left[\eta^{6}-\left(\mathrm{C}_{6} \mathrm{H}_{5}\right) \mathrm{B}^{-}\left(\mathrm{C}_{6} \mathrm{H}_{5}\right)_{3}\right](2.06$ $\mathrm{mg}, 0.004 \mathrm{mmol})$ in THF $(0.10 \mathrm{~mL})$ was added to a solution of M-PMMA (102 mg, $0.08 \mathrm{mmol})$ in THF $(0.30 \mathrm{~mL})$ under argon. After polymerization at $30^{\circ} \mathrm{C}$ for $24 \mathrm{~h}$, the solution was added to a large amount of diethyl ether to precipitate the product poly(M-PMMA) [diethyl ether is a good solvent for M-PMMA and a poor solvent for poly(M-PMMA)]. The resultant polymer was collected, filtered, and dried under reduced pressure until constant weight. Yield: $85 \%$. GPC (THF): $M_{\mathrm{w}}=136,000, M_{\mathrm{w}} / M_{\mathrm{n}}=$ 5.6. Weight-average degree of polymerization $\left(\mathrm{DP}_{\mathrm{w}}\right)$ of main chain $=80 .[\alpha]_{\mathrm{D}}=+166^{\circ} \quad(c=0.10 \mathrm{~g} / \mathrm{dL}$, THF, r.t.). ${ }^{1} \mathrm{H}$ NMR $\left(400 \mathrm{MHz}, \mathrm{CDCl}_{3}\right): \delta=5.35$ (s, $\mathrm{CHCH}_{3}$ ), 3.73 (s, terminal $\mathrm{CO}_{2} \mathrm{CH}_{3}$ ), 3.70-3.30 (broad s, $\mathrm{CO}_{2} \mathrm{CH}_{3}$ on backbone), 2.80-2.60 (broad $\mathrm{m}, \mathrm{CH}_{2}$ of terminal MMA moiety), 2.20-0.60 (broad $\mathrm{m}, \mathrm{CH}_{2}$ and $\mathrm{CH}_{3}$ of backbone), $1.47\left(\mathrm{~s}, \mathrm{CHCH}_{3}\right)$. The signal assigned to olefinic protons on the main chain was not observed probably due to its broadness.

\section{RESULTS AND DISCUSSION}

The PMMA macromonomer bearing an acetylene chain end (M-PMMA) was prepared by the ATRP of MMA using 1 as initiator in the presence of $\mathrm{CuBr} / \mathrm{PMDETA}$ as catalyst/ligand system in toluene 


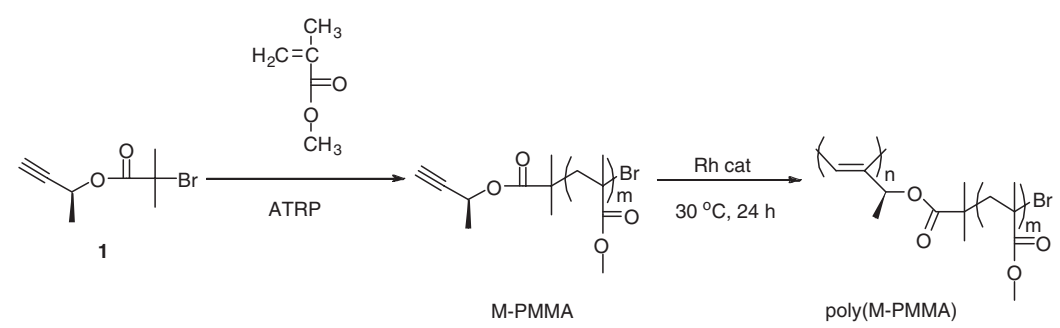

Scheme 1. Synthesis of M-PMMA and poly(M-PMMA).

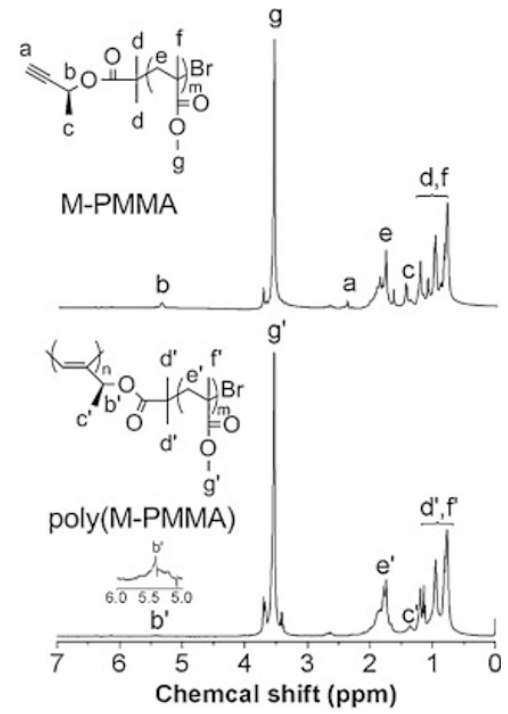

Figure 1. ${ }^{1} \mathrm{H}$ NMR spectra of M-PMMA and poly(MPMMA).

at $70{ }^{\circ} \mathrm{C}$ (Scheme 1). It is known that the reactivity of macromonomer decreases with increasing molecular weight because of the increasing sterical hindrance of PMMA chains attached to the polymerizable acetylene group. ${ }^{48}$ Thus the molar monomer-to-initiator ratio in the feed was chosen to be $10: 1$ in order to obtain a low molecular weight macromonomer. As a result, the $M_{\mathrm{w}}$ and $M_{\mathrm{w}} / M_{\mathrm{n}}$ of PMMA were 1690 and 1.3 , respectively, according to gel permeation chromatography (GPC). The well-defined structure of M-PMMA was verified by ${ }^{1} \mathrm{H}$ NMR analysis (see Figure 1 and Experimental Section).

The macromonomer M-PMMA was polymerized with a zwitter ionic complex (nbd) $\mathrm{Rh}^{+}\left[\eta^{6}-\left(\mathrm{C}_{6} \mathrm{H}_{5}\right) \mathrm{B}^{-}-\right.$ $\left.\left(\mathrm{C}_{6} \mathrm{H}_{5}\right)_{3}\right]$, which is frequently employed in the polymerization of monosubstituted acetylenes, in THF at $30{ }^{\circ} \mathrm{C}$. The variation of monomer and catalyst concentrations led to the formation of poly(macromonomers) [poly(M-PMMA)] with different molecular weights as listed in Table I. As seen in Run 1, poly(M-PMMA) was formed in a good yield of $73 \%$ under the conditions of $[\mathrm{M}-\mathrm{PS}]=0.1 \mathrm{M}$ and $[\mathrm{Rh}]=5.0 \mathrm{mM}$, and possessed an $M_{\mathrm{w}}$ of 48,200 and an $M_{\mathrm{w}} / M_{\mathrm{n}}$ of 4.0 . Increasing the catalyst concentration to $10 \mathrm{mM}$, polymer with a lower molecular weight and a narrower
Table II. Solvent effects on the polymerization of M-PMMA $\left(M_{\mathrm{w}}=1690, M_{\mathrm{w}} / M_{\mathrm{n}}=1.3\right)$ with (nbd) $\mathrm{Rh}^{+}\left[\eta^{6}-\left(\mathrm{C}_{6} \mathrm{H}_{5}\right) \mathrm{B}^{-}\left(\mathrm{C}_{6} \mathrm{H}_{5}\right)_{3}\right]^{\mathrm{a}}$

\begin{tabular}{ccccccc}
\hline \multirow{2}{*}{ Run } & Solvent & \begin{tabular}{c} 
Poly(M-PMMA $)^{\mathrm{b}}$ \\
\cline { 3 - 7 }
\end{tabular} & $\begin{array}{c}\text { Yield } \\
(\%)\end{array}$ & $M_{\mathrm{w}}{ }^{\mathrm{c}}$ & $M_{\mathrm{w}} / M_{\mathrm{n}}{ }^{\mathrm{c}}$ & $\mathrm{DP}_{\mathrm{w}}{ }^{\mathrm{d}}\left[\begin{array}{r}{[\alpha]_{\mathrm{D}}{ }^{\mathrm{e}}} \\
(\mathrm{deg})\end{array}\right.$ \\
\hline 1 & $\mathrm{THF}$ & 85 & 136,000 & 5.6 & 80 & 166 \\
2 & $\mathrm{CHCl}_{3}$ & 69 & 25,900 & 3.5 & 15 & 87 \\
3 & Toluene & 63 & 39,600 & 4.1 & 23 & 102 \\
4 & $o$-Dichlorobenzene & 58 & 68,900 & 4.9 & 41 & 125 \\
\hline \multicolumn{5}{c}{${ }^{\mathrm{a}}$ Conditions: [M-PMMA] $=0.20 \mathrm{M},[\mathrm{Rh}]=10 \mathrm{mM}, 30^{\circ} \mathrm{C}}$,
\end{tabular}
$24 \mathrm{~h}$. ${ }^{\mathrm{b}}$ Diethyl ether-insoluble product. ${ }^{\mathrm{c}}$ Estimated by GPC in THF on the basis of a PS calibration. ${ }^{\mathrm{d}}$ Weight-average degree of polymerization (calculated by $M_{\mathrm{w}, \text { poly(M-PMMA) }} / M_{\mathrm{w}, \mathrm{M}-\mathrm{PMMA}}$, $\left.M_{\mathrm{w}, \mathrm{M}-\mathrm{PMMA}}=1690\right)$. ${ }^{\mathrm{e}}$ Measured by polarimetry at room temperature, $c=0.1 \mathrm{~g} / \mathrm{dL}$ in $\mathrm{CHCl}_{3}$.

molecular weight distribution $\left(M_{\mathrm{w}}=32,500, M_{\mathrm{w}} /\right.$ $\left.M_{\mathrm{n}}=3.6\right)$ was produced in a higher yield $(81 \%)$ (Run 2). Changing the macromonomer concentration to $0.2 \mathrm{M}$ with keeping a catalyst concentration of $5 \mathrm{mM}$ effectively improved the molecular weight $\left(M_{\mathrm{w}}=105,000\right)$ but the value of $M_{\mathrm{w}} / M_{\mathrm{n}}$ became broader $\left(M_{\mathrm{w}} / M_{\mathrm{n}}=8.4\right)$ (Run 3). Further, increasing the catalyst concentration to $10 \mathrm{mM}$ led to a polymer with a high molecular weight $\left(M_{\mathrm{w}}=136,000\right)$ and an $M_{\mathrm{w}} / M_{\mathrm{n}}$ of 5.6 in a good yield (85\%) (Run 4$)$.

Solvent effects on the polymerization of M-PMMA were examined, whose results are shown in Table II. The polymerization in $\mathrm{CHCl}_{3}$ resulted in a low molecular weight polymer $\left(M_{\mathrm{w}}=25,900\right)$ in a good yield ( $70 \%$ ) (Run 2). Toluene as solvent did not enhance the molecular weight $\left(M_{\mathrm{w}}=39,600\right)$ and yield $(63 \%)$. $o$-Dichlorobenzene led to a relatively high molecular weight $\left(M_{\mathrm{w}}=68,900\right)$ but the yield was modest (58\%) (Run 4). Thus, among the solvents examined, THF was the most favorable with respect to both polymer yield and molecular weight. Poly(M-PMMA) was a light yellow solid soluble in THF, $\mathrm{CHCl}_{3}$, toluene, acetone and DMF, but insoluble in diethyl ether, $\mathrm{MeOH}$, hexane and DMSO. By contrast, the reported poly(M-PS) is insoluble in acetone. ${ }^{54}$

The structure of poly(M-PMMA) was characterized by ${ }^{1} \mathrm{H}$ NMR. Figure 1 shows the ${ }^{1} \mathrm{H}$ NMR spectra of 


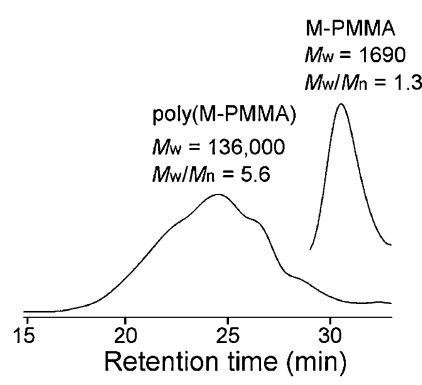

Figure 2. GPC curves of M-PMMA and poly(M-PMMA) (Run 4, Table I) measured with THF as an eluent using linear PS standards.

poly(M-PMMA) as well as its monomer M-PMMA for comparison. The resonance peak $(\delta=2.39 \mathrm{ppm})$ of the acetylenic proton observed in the ${ }^{1} \mathrm{H}$ NMR spectrum of M-PMMA disappeared completely in that of poly(M-PMMA). This indicates that polymerization occurred through the addition reaction of the triple bond of the macromonomer as expected. The $\mathrm{Rh}$ catalyst, (nbd) $\mathrm{Rh}^{+}\left[\eta^{6}-\left(\mathrm{C}_{6} \mathrm{H}_{5}\right) \mathrm{B}^{-}\left(\mathrm{C}_{6} \mathrm{H}_{5}\right)_{3}\right]$, is known to produce stereoregular cis-transoidal polyacetylenes, which display a sharp signal at $6.0-6.5 \mathrm{ppm}$ due to the olefinic proton in the main chain. ${ }^{24-29}$ However, the cis olefinic proton signal was not observed in the ${ }^{1} \mathrm{H}$ NMR spectrum of poly(M-PMMA), probably because of the low mobility of the polyacetylene main chain. ${ }^{50}$

The GPC traces of M-PMMA and poly(M-PMMA) (Run 4, Table I) are illustrated in Figure 2. The GPC peak of poly(M-PMMA) shifted to a high molecular weight region $\left(M_{\mathrm{w}}=136,000\right)$ without any tailed trace of the residual macromonomer. This indicates that the use of diethyl ether as the precipitant proved to be feasible for the purification of the product [it is a good solvent for M-PMMA but a non-solvent for poly(M-PMMA)]. The weight-average degrees of polymerization $\left(\mathrm{DP}_{\mathrm{w}}\right)$ of poly(M-PMMA)s were calculated to be in the range of $15-80$ based on the $M_{\mathrm{w}}$ of the macromonomer as listed in Tables I and II.

Poly(M-PMMA) displayed relatively small optical rotations $\left([\alpha]_{\mathrm{D}}=+87^{\circ}-+166^{\circ}\right.$, see Table II), which were opposite in sign to the value of M-PMMA $\left([\alpha]_{\mathrm{D}}=-10^{\circ}\right)$. However, poly(M-PMMA) (Run 4, Table I) exhibited strong CD effects at around 350$357 \mathrm{~nm}$ with molar ellipticities $([\theta])$ of +26300 $+27500 \mathrm{deg} \mathrm{cm}^{2} \mathrm{dmol}^{-1}$ in THF, $\mathrm{CHCl}_{3}$, toluene and DMF (Figure 3). The CD patterns in these solvents were similar to one another. Since the solution of M-PMMA was CD-inactive at wavelength longer than $300 \mathrm{~nm}$, the CD bands at $350-357 \mathrm{~nm}$ should correspond to the absorption of the segments of the polyene backbone of poly(M-PMMA), thus unambiguously confirming that its polyene chain possessed a helical conformation with an excess of one-handedness.

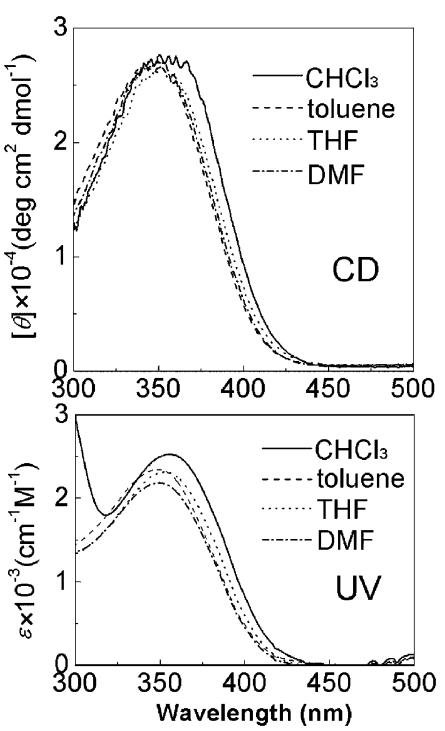

Figure 3. CD and UV-vis spectra of poly(M-PMMA) (Run 4, Table I) measured in toluene, THF, $\mathrm{CHCl}_{3}$, and DMF $(c=0.76$ $\mathrm{mM})$ at $20^{\circ} \mathrm{C}$.

Other polymer samples in Tables I and II also showed similar CD and UV-vis spectra. It is noted that the DPs of poly(M-PMMA) are high enough for the formation of helix albeit they are relatively small. This can be attributed to the remarkable ability of the chiral moiety adjacent to the main chain to induce helicity. ${ }^{53}$ The UV-vis absorption maximum and CD signal of poly(M-PMMA) appeared in the region of 350-357 $\mathrm{nm}$, which are red-shifted compared to those of $(S)$ 1-methylpropargyl alcohol $(305-315 \mathrm{~nm})$ and its ester derivatives $(323-328 \mathrm{~nm}){ }^{53}$ This indicates that poly(M-PMMA) has a longer conjugated main chain than those of (S)-1-methylpropargyl alcohol and its ester derivatives, and that poly(M-PMMA) forms a rather relaxed helical conformation presumably due to the bulky side PMMA chains.

The variable-temperature $\mathrm{CD}$ and UV spectra of poly(M-PMMA) (Run 4, Table I) were measured in toluene in the range of 0 to $60^{\circ} \mathrm{C}$ to examine the thermal stability of the helical conformation (Figure 4). The shape of CD signal hardly changed with temperature, although the intensity slightly decreased with increasing temperature. It is assumed that the main chain of poly(M-PMMA) takes practically one-handed helical structure which is stable toward temperature, and that the persistence length of helix only slightly increases at low temperature. These results give a contrast to that of the previously reported case that the intensities of CD signals and/or specific rotations of helical poly( $\mathrm{N}$-propargylamides) and poly(phenylacetylenes) considerably decrease as temperature is raised. ${ }^{60,61}$ This phenomenon can be explained by the idea that the main chain of these polymers is quite flexible so that the regular helical form is readily 


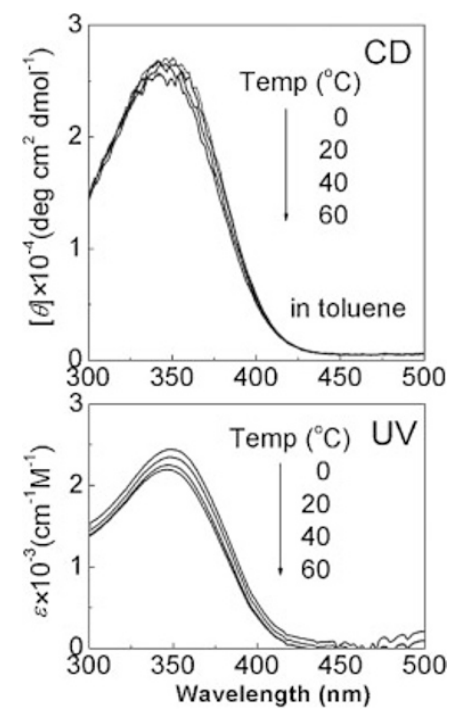

Figure 4. Variable temperature $\mathrm{CD}$ spectra of poly(MPMMA) (Run 4, Table I) in toluene $(c=0.76 \mathrm{mM})$.

transformed into more or less irregular random-coiled structure by thermal stimulus. On the other hand, the present poly(macromonomer) possesses a rigid main chain, and eventually, the helix of poly(M-PMMA) is thermally more stable than those of other substituted polyacetylenes. The chiroptical properties of poly(M-PMMA) were basically the same as those of the corresponding PS side chain-containing poly(macromonomer), namely, the helix was sufficiently stable to solvents and temperature. ${ }^{54}$

Acknowledgment. The authors thank Prof. Sanda and Mr. Suzuki at Department of Polymer Chemistry, Kyoto University for the measurement of CD and UVvis spectra and helpful discussions. W.Z. acknowledges Scholarship from the Ministry of Education, Culture, Sports, Science and Technology, Japan. This research was partly supported by a Grant-in-Aid for Scientific Research in a Priority Area "SuperHierarchical Structures (No. 446)" from the Ministry of Education, Culture, Sports, Science and Technology, Japan.

\section{REFERENCES}

1. E. Yashima, K. Maeda, and T. Nishimura, Chem. Eur. J., 42, 10 (2004).

2. D. J. Hill, M. J. Mio, R. B. Prince, T. S. Hughes, and J. S. Moore, Chem. Rev., 101, 3893 (2001).

3. T. Nakano and Y. Okamoto, Chem. Rev., 101, 4013 (2001).

4. J. J. L. M. Cornelissen, A. E. Rowan, R. J. M. Nolte, and N. A. J. M. Sommerdijk, Chem. Rev., 101, 4039 (2001).

5. M. M. Green, K.-S. Cheon, S.-Y. Yang, J.-W. Park, S. Swansburg, and W. Liu, Acc. Chem. Res., 34, 672 (2001).

6. S. Habaue, T. Tanaka, and Y. Okamoto, Macromolecules, 28, 5973 (1995).
7. Y. Okamoto, M. Nishikawa, T. Nakano, E. Yashima, and K. Hatada, Macromolecules, 28, 5135 (1995).

8. T. Nakano, Y. Okamoto, and K. Hatada, J. Am. Chem. Soc., 114, 1318 (1992).

9. Y. Okamoto, K. Suzuki, K. Ohta, K. Hatada, and H. Yuki, J. Am. Chem. Soc., 101, 4763 (1979).

10. K. Ute, K. Hirose, H. Kashimoto, K. Hatada, and O. Vogl, J. Am. Chem. Soc., 113, 6305 (1991).

11. L. S. Corley and O. Vogl, Polym. Bull., 3, 211 (1980).

12. K. Onitsuka, T. Mori, M. Yamamoto, F. Takei, and S. Takahashi, Macromolecules, 39, 7224 (2006).

13. J. J. L. M. Cornelissen, W. S. Graswinckel, A. E. Rowan, N. A. J. M. Sommerdijk, and R. J. M. Nolte, J. Polym. Sci., Part A: Polym. Chem., 41, 1725 (2003).

14. T. J. Deming and B. M. Novak, J. Am. Chem. Soc., 115, 9101 (1993).

15. P. C. J. Kamer, R. J. M. Nolte, and W. J. Drenth, J. Am. Chem. Soc., 110, 4063 (1988).

16. B. T. Muellers, J. W. Park, M. S. Brookhart, and M. M. Green, Macromolecules, 34, 572 (2001).

17. M. M. Green, J. Park, T. Sato, A. Teramoto, S. Lifson, R. L. B. Selinger, and J. V. Selinger, Angew. Chem., Int. Ed., 38, 3139 (1999).

18. M. M. Green, C. Andreola, B. Muñoz, M. P. Reidy, and K. Zero, J. Am. Chem. Soc., 110, 4063 (1988).

19. M. Goodman and S. Chen, Macromolecules, 4, 398 (1970).

20. A. Saxena, R. Rai, S. Y. Kim, M. Fujiki, M. Naito, K. Okoshi, and G. Kwak, J. Polym. Sci., Part A: Polym. Chem., 44, 5060 (2005).

21. T. Sato, K. Terao, A. Teramoto, and M. Fujiki, Polymer, 44, 5477 (2003).

22. M. Fujiki, J. Am. Chem. Soc., 116, 6017 (1994).

23. M. Fujiki, J. Am. Chem. Soc., 116, 11976 (1994).

24. J. Tabei, M. Shiotsuki, F. Sanda, and T. Masuda, Macromolecules, 38, 5860 (2005).

25. J. Tabei, R. Nomura, M. Shiotsuki, F. Sanda, and T. Masuda, Macromol. Chem. Phys., 206, 323 (2005).

26. J. Deng, J. Tabei, M. Shiotsuki, F. Sanda, and T. Masuda, Macromolecules, 37, 7156 (2004).

27. J. Deng, J. Tabei, M. Shiotsuki, F. Sanda, and T. Masuda, Macromolecules, 37, 5149 (2004).

28. J. Tabei, R. Nomura, and T. Masuda, Macromolecules, 35, 5404 (2002).

29. R. Nomura, J. Tabei, and T. Masuda, J. Am. Chem. Soc., 123, 8430 (2001).

30. H. Nakako, R. Nomura, and T. Masuda, Macromolecules, 34, 1496 (2001).

31. H. Nakako, Y. Mayahara, R. Nomura, M. Tabata, and T. Masuda, Macromolecules, 33, 3978 (2000).

32. R. Nomura, H. Fukushima, H. Nakako, and T. Masuda, J. Am. Chem. Soc., 122, 8830 (2000).

33. H. Nakako, R. Nomura, M. Tabata, and T. Masuda, Macromolecules, 32, 2861 (1999).

34. H. Onouchi, T. Hasegawa, D. Kashiwagi, H. Ishiguro, K. Maeda, and E. Yashima, Macromolecules, 38, 8625 (2005).

35. K. Morino, M. Oobo, and E. Yashima, Macromolecules, 38, 3461 (2005).

36. H. Zhao, F. Sanda, and T. Masuda, Polymer, 46, 2841 (2005). 
37. F. Sanda, K. Terada, and T. Masuda, Macromolecules, 38, 8149 (2005).

38. J. W. Y. Lam and B. Z. Tang, Acc. Chem. Res., 38, 745 (2005).

39. G. Gao, F. Sanda, and T. Masuda, Macromolecules, 36, 3932 (2003).

40. B. S. Li, K. K. L. Cheuk, L. S. Ling, J. W. Chen, X. D. Xiao, C. L. Bai, and B. Z. Tang, Macromolecules, 36, 77 (2003).

41. J. Kadokawa, K. Tawa, M. Suenaga, Y. Kaneko, and M. Tabata, J. Macromol. Sci., Part A: Pure Appl. Chem., 43, 1179 (2006).

42. I. Otsuka, R. Sakai, T. Satoh, R. Kakuchi, H. Kaga, and T. Kakuchi, J. Polym. Sci., Part A: Polym. Chem., 43, 5855 (2005).

43. K. Matuura, S. FuRuno, and K. Kobayashi, Chem. Lett., 27, 847 (1998).

44. T. Aoki, K.-i. Shinohara, T. Kaneko, and E. Oikawa, Macromolecules, 29, 4192 (1996).

45. Y. Suzuki, M. Shiotsuki, F. Sanda, and T. Masuda, Macromolecules, 40, 1864 (2007).

46. M. Zhang and A. H. E. Mueller, J. Polym. Sci., Part A: Polym. Chem., 43, 3461 (2005).

47. N. Hadjichristidis, M. Pitsikalis, H. Iatrou, and S. Pispas, Macromol. Rapid. Commun., 24, 979 (2003).

48. K. Ito and S. Kawaguchi, Adv. Polym. Sci., 142, 129 (1999).
49. W. Zhang, M. Shiotsuki, and T. Masuda, Macromol. Chem. Phys., 207, 933 (2006).

50. W. Zhang, M. Shiotsuki, T. Masuda, J. Kumaki, and E. Yashima, Macromolecules, 40, 178 (2007).

51. W. Zhang, M. Shiotsuki, and T. Masuda, Macromolecules, 40, 1421 (2007).

52. W. Zhang, M. Shiotsuki, and T. Masuda, Polymer, 48, 2548 (2007).

53. K. Maeda, N. Kamiya, and E. Yashima, Chem. Eur. J., 10, 4000 (2004).

54. W. Zhang, M. Shiotsuki, and T. Masuda, Macromol. Rapid. Commun., in press.

55. K. Matyjaszewski, Prog. Polym. Sci., 30, 858 (2005).

56. K. Matyjaszewski and J. Xia, Chem. Rev., 101, 2921 (2001).

57. M. Kamigaito, T. Ando, and M. Sawamoto, Chem. Rev., 101, 3689 (2001).

58. V. Coessens, T. Pintauer, and K. Matyjaszewski, Prog. Polym. Sci., 26, 337 (2001).

59. R. R. Schrock and J. A. Osborn, Inorg. Chem., 9, 2339 (1970).

60. T. Aoki, M. Kokai, K. Shinohara, and E. Oikawa, Chem. Lett., 22, 2009 (1993).

61. F. Ciardelli, S. Lanzillo, and O. Pieroni, Macromolecules, 7 , 174 (1974). 